\title{
An Accessibility Study of Fire Evacuation at Dukuh Atas MRT Station
}

\author{
A. Muqorrobin ${ }^{1}$ E. Supriyatna ${ }^{2 *}$ F. Lianto ${ }^{2}$ N. W. Priyomarsono ${ }^{2}$ \\ ${ }^{1}$ Student of Master of Architecture, Department of Architecture, Universitas Tarumanagara, Jakarta, Indonesia \\ ${ }^{2}$ Lecturer of Master of Architecture, Department of Architecture, Universitas Tarumanagara, Jakarta, Indonesia \\ *Corresponding author. Email: eddysmarizar@yahoo.com
}

\begin{abstract}
The Station of MRT Dukuh Atas is planned as the deepest station, which has a depth of \pm 20 meters. It is an interchange station that allows there are many people in the basement so that in case of fire requires the process of rapid evacuation. This research will examine the accessibility of fire evacuation, whether it meets the regulatory standard is used as a reference. The research method used is a case study qualitative approach. The data of the Station of MRT Dukuh Atas, such as documentation, interviews, drawing a plan, are then linked to analytical tools in the form of theories and regulations. The results of the analysis will be tested by conducting evacuation simulations in the field as a research validation. The result found that the door, staircase, exit door, corridor, ventilation, and sprinklers are already followed the regulation of NFPA 130/2017 and MLIT 2004, except for the Escalators and gathering points.
\end{abstract}

Keywords: Accessibility, Fire Evacuation, MRT Station, NFPA 130/2017, MILIT 2004

\section{INTRODUCTION}

The book Urban Rail Transit explains that the main thing in the success of designing a transit station is its accessibility. Designing transit stations, architects need to accommodate the space requirements of users from various groups [1]. The accessibility standard is something that allows being used in making facilities accessible by building users [2].

The accessibility of inadequate evacuation at the station occurred in 2003 in Daegu, Korea. Many of the victims who died in the fire were caused by the pattern of spatial and the complexity of the station building, which was difficult and hindered passengers in the evacuation process. The principle of fire safety design at an underground station is evacuation security [3]. Failures in design planning at the station also occurred in 2015; an accident happened at a station in Washington, USA, which resulted in 1 passenger died. More than 80 people were treated for inhaling smoke from a fire that shorted the electric current.

Akmalia Zain, the Specialist Chief of the Railroad Planning \& Department of Road Development and Authority of Transportation, Dubai Government in an open discussion of the Architecture Association Indonesia (IAI) Jakarta also believes that the source of the fire triggers fires often inflict from the platform floor and train circuits, the level of the platform is in the deepest position makes the smoke spread upwards, so that, it will trigger smoke on every floor above it. The uncomplicated accessibility planning and the position of the smoke lobby are easily achieved becomes the key to success in the fire disaster evacuation process. Meanwhile, according to the City Architectural Building Expert Team, Martinus Izaak, during fires, smoke is more dangerous for passengers than fire. Smoke spread quickly so that passengers ran out of oxygen. The walls of the building have enough fire resistance to make passengers save themselves.

The Station of Dukuh Atas is planned as an interchange station that has a depth of \pm 20 meters to this land, and it will be connected to several other modes of transportation. The train of Mass Rapid Transit (MRT) Jakarta consists of 16 train cars for operation and two reserves. One series consists of 6 vehicles and 1,200-1,800 people in one sequence, the period from one train to another is around 1015 minutes, so there will be thousands of people moving out and entering the station is suspected of having problems in the accessibility of evacuation.

The purpose of this research is to produce recommendations or guidelines in designing the accessibility of evacuation at underground stations of MRT based on research and simulations in the field.

\section{BACKGROUND}

\subsection{Research Framework}

This below is Figure 1 below explains that the research framework compiled in conducting this research. 


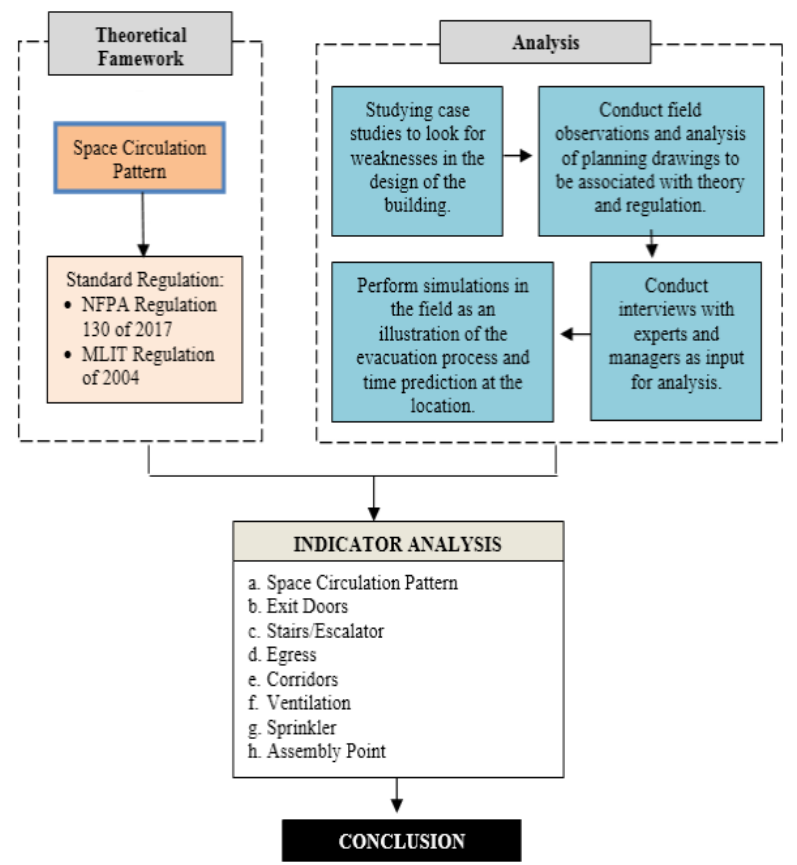

Figure 1. Research Framework Source: Authors, 2019

\subsection{Theories and Standards of Regulation}

Some theories form the basis of this research, and it is supported by regulations and journals related to the topics that have been discussed. The following is a summary of the theories and regulations used as indicators in this study.

1. Types of space circulation patterns, according to DK. Ching (2007) [4], as follows:

a. Linear is a straight path that can form elements of organizing a series of spaces.

b. Radial is a pattern that has a straightforward way and develops from a shared center.

c. A Spiral is a single path that is from a central point. Then it continuously surrounds the center with a further distance from the center.

d. Grid is a pattern that consists of two sets of parallel lines that intersect so to create a field of square space.

e. The network is a pattern of lines connecting points in a space.

f. Composite is a combination of circulation patterns that have been mentioned above.

2. The Standard of Regulation NFPA 130/2017 [5] and MLIT 2004 [6].
a. Exit door
b. Staircase \& Escalators
c. Exit way
d. Corridor
e. Ventilation
f. Sprinkler
g. Assembly Point

\section{METHODS}

The research method used was a qualitative study - a case study. The data at the Station of the MRT Hamlet Atas, such as documentation, interviews, drawing a plan, and then is linked to analytical tools in the form of theory and previous regulations. The results of the analysis were then tested by conducting an evacuation simulation in the field as research validation.

The research method used was a literature study approach with fire safety standards, which was a guideline planning of MRT in Jakarta. For instance, NFPA 130 in 2017 and MLIT in 2004, as well as interviews with academics, practitioners, and managers of MRT. The results of the analysis were then tested by conducting an evacuation simulation in the field as research validation.

\section{FINDINGS AND DISCUSSIONS}

\subsection{The Pattern of Space Circulation}

The circulation pattern of space at the MRT Station is in the form of a linear way. It provides advantages in designing stations that have elongated space requirements, such as simple circulation patterns make it easier for passengers in the evacuation process, minimizing the possibility of passengers getting lost because there are no forked roads. It reduces the congestion node will prevent passenger evacuation.

\subsection{Exit Doors}

Based on the survey and analysis in the figure, the design of The MRT Station of Dukuh Atas is looked to minimize the number of doors on the evacuation route, there are only two doors from the platform (B-3) to the concourse (B-1), on the Peron Floor (B-3) on evacuation routes located on a staircase. The door with iron plate material has a width of $1.35 \mathrm{~m}$. It opens in the same direction as the passenger at the time of evacuation by NFPA 130/2017 and MLIT 2004 regulations (Figure 2).

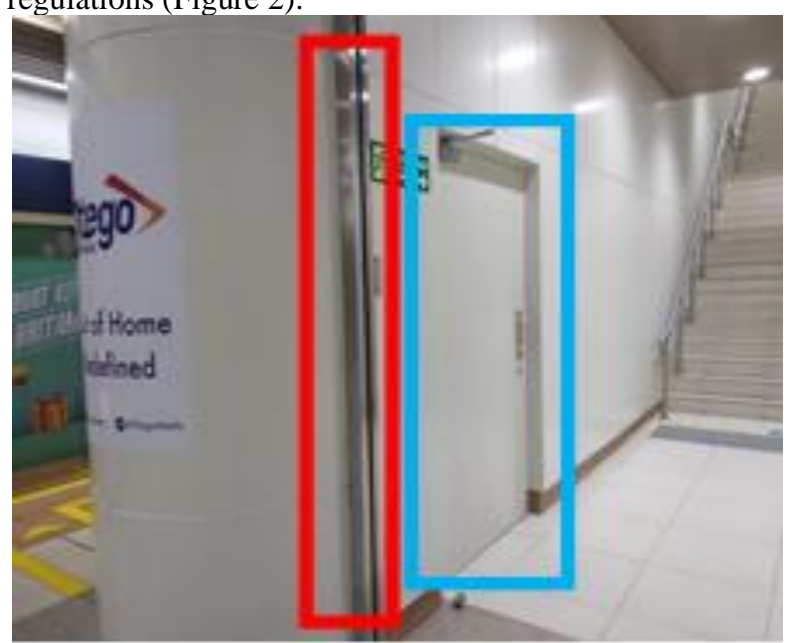



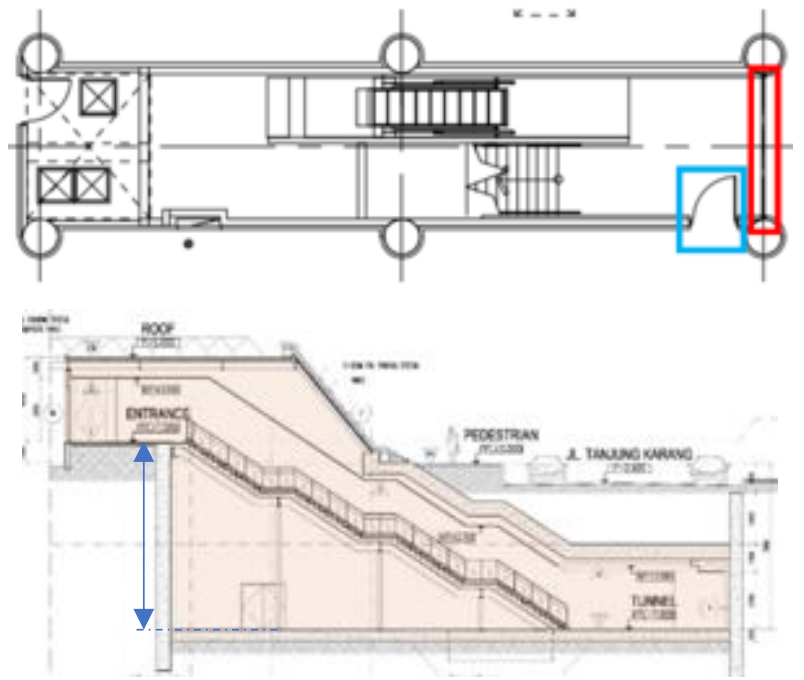

Figure 2. The door on the Station Platform Floor Source: Authors, 2019

Meanwhile, on the Concourse Floor (B-1) there are no doors, but there are several Tapping Gate paths has $60 \mathrm{~cm}$ wide on the evacuation route. At NFPA, the requirements for Tapping Gate must be rotated manually during evacuation. Based on an interview with the Head of Jakarta's MRT Engineering Division, Weni, who states that the Tapping Gate on the Concourse Floor will open automatically when a fire, earthquake, or flood strikes.

Peron Floor (B-3) of the station, researchers observe that there are doors are planned as fire doors, and there are rolling doors that have a function as fire or smoke compartments during fires. Based on interviews with Ir. Martinus Izaak, IAI., who argues that these designs have been carried out abroad, they no longer make fire protection, but it relies on walls or rolling doors as smoke or fire separators when the fire will be closed automatically to prevent the spread of fire or smoke, after being closed passengers will enter the evacuation staircase through the fire door.

\subsection{Staircase and Escalator}

Based on interviews with passengers, the majority of them are not too disturbed by the height of the staircase at the Station of Dukuh Atas; it is due to the use of the staircase when going down is more relaxed, while traveling can use an escalator. Pregnant women, the elderly, and the disabled can use the elevator to go up and down to the Platform Floor. The MRT Station of Dukuh Atas is designed as the deepest station with has a staircase from the Concourse Floor (B-1) to the Platform Floor (B-3) in which is relatively high (Figure 3 ). This ladder has a depth of 8.85 meters; it is divided into 52 staircases with three boundaries.

Based on interviews with Prof. Yulianto, who argues that the height of the staircase from the Concourse Floor to the Platform Floor is still relatively short so that passengers can still access the staircase and have elevators for the disabled.
While Ir. Martinus Izaak also explains that the height of the staircase at this station is possible as long as they refer to the rules, i.e., every 15-18 steps are given a landing as a rest for people who climb/go down the staircase.

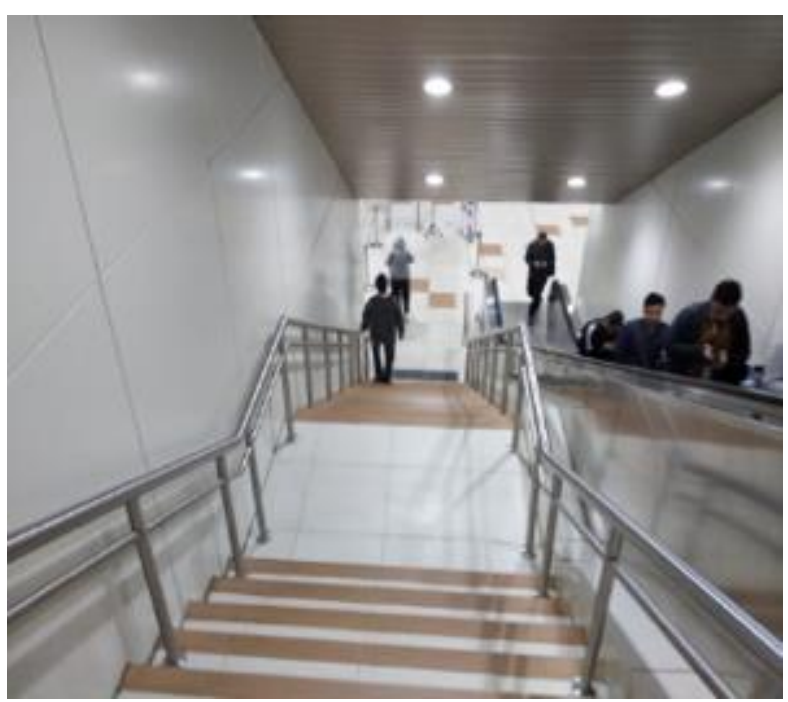

Figure 3. The Section of Stair from the Concourse Floor (B.1) to the Platform Floor (B.3)

Source: Authors, 2019

There are two escalators on the evacuation route on the Platform Floor (B-3) to the Concourse Floor and Concourse Floor to the Ground Floor. The escalator width of $100 \mathrm{~cm}$ is still not by NFPA 130/2017 regulation, which has a standard of $110 \mathrm{~cm}$. The use of fiber and rubber materials so that it is not slippery and slippage has been by the requirement of NFPA 130 and MLIT 2004.

\subsection{Egress}

The egress facilities need to accommodate an appropriate size and distance when evacuating people. It was explained that in the NFPA 130/2017 requirements, the distance between the farthest points occupied by passengers must not exceed 100 meters from the door means the egress (staircase). Based on the analysis on the floor of Platform (B-3), which researchers conducted to discover passengers occupy the farthest distance to the exit point, the center of the station is the furthest distance \pm 55 meters to reach the egress because of the elongated station. Is placed the staircase on the left side and right; thus, the center is the furthest distance. Passengers can reach analysis on the Concourse Floor (B-1), the farthest point in the area is 90 meters to the egress (staircase). In comparison, the closest distance from the passenger point to the egress (staircase) is 40 meters (Figure 4). Based on this analysis, the distance of the passenger range to the exit point is still below 100 meters and complies with NFPA 130 regulations. 


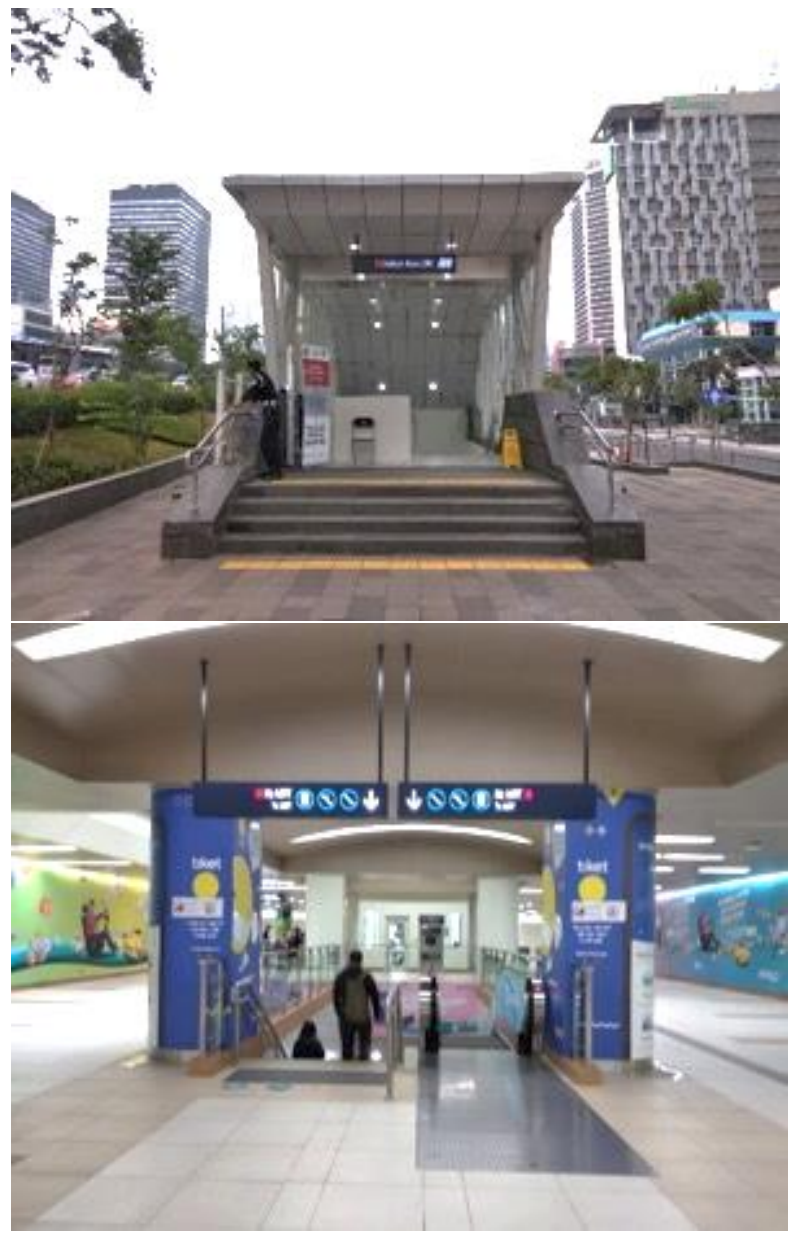

Figure 4. The egress on the Station Concourse Floor and First Floor

Source: Authors, 2019

Regarding the time required in the evacuation process according to NFPA 130/2017 regulations states that the evacuation time in the platform area to the emergency exit is a maximum of 4 minutes, from the platform to the safe gathering point for a maximum of 6 minutes, it is given an additional two minutes for each additional floor. Whereas MLIT asserts that the evacuation process depends on the performance of mechanical ventilation. Based on interviews with Ir. Martinus Izaak, IAI who argues that at the MRT Station Upper Floor Utility Floor (B-2) is counted as an additional 2 minutes, so the evacuation process at this station takes a maximum of 12 minutes to bring all passengers to the assembly point on the ground floor. Meanwhile, according to Prof. Yulianto points out that The Station of Dukuh Atas uses a performance-based formula that has a smoke removal speed formula compared to the evacuation time, so the time calculation based on NFPA 130 will not match this station.

The results of this evacuation simulation show that the speed of Indonesians in evacuating even the slowest is still below the standard required by NFPA 130/2017 or MLIT 2004 (Table 1).
Table 1. The Result of Evacuation Simulation Toward Several Classifications of MRT Users

EVACUATION SIMULATION AT DUKUH ATAS

\begin{tabular}{l|l} 
1. Elderly (age 50 years old) & 3,50 minutes \\
2. Women (wearing skirt) & 3,30 minutes \\
3. Fat Men & 3,35 minutes \\
\hline
\end{tabular}

Source: Authors, 2019

\subsection{Corridor}

The corridor is the important thing to be discussed in analyzing evacuation routes; is due to the corridor has several requirements that must be accommodated in designing a plan. Based on interviews with passengers, most passengers who use the MRT as a means of daily transportation feel the width of the corridor is quite wide, so there is no dispute between passengers even during peak hours. In the Peron Floor area (B-3), the width of the smallest corridor is 3.7 meters, and the largest corridor is 12 meters (Figure 5).

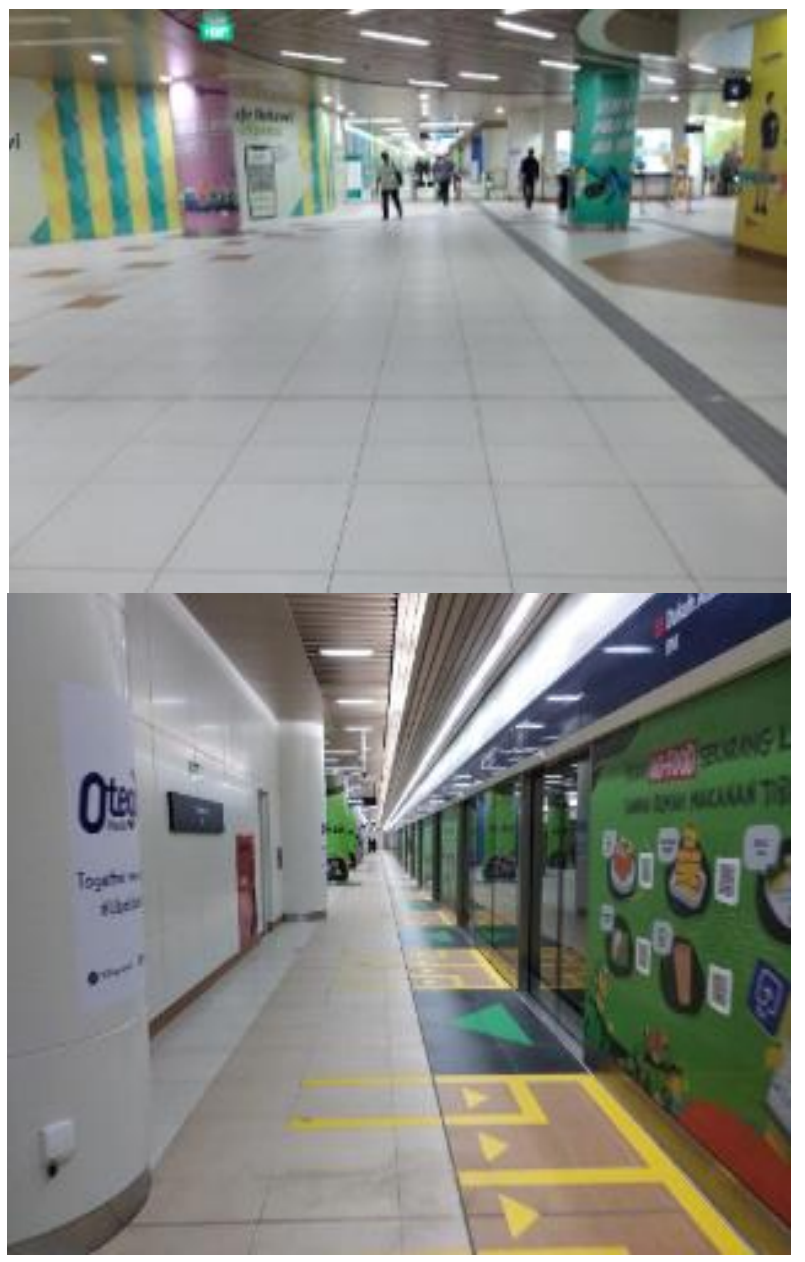




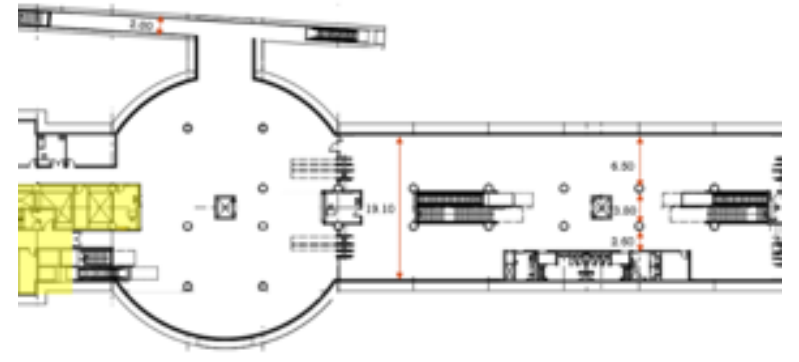

Figure 5. The corridors on the Station Concourse Floor and Platform Floor

Source: Authors, 2019

The floor of the Concourse looks wider than Platform Floor (B-3) because all passenger facilities are located on this floor. The width of the largest corridor is 19.1 meters, with the smallest corridor of 2 meters. According to Ir. Martinus Izaak, IAI., that the corridor regulation in buildings is measured in length and width so that the corridor is calculated for functional needs.

\subsection{Ventilation}

There are two mechanical ventilation towers that have a function at this station. Besides air, this station also has natural lighting ventilation; there are two pieces in the station's garden. This natural lighting effects the delivery of light to the Concourse Floor (B-1) (Figure 6).
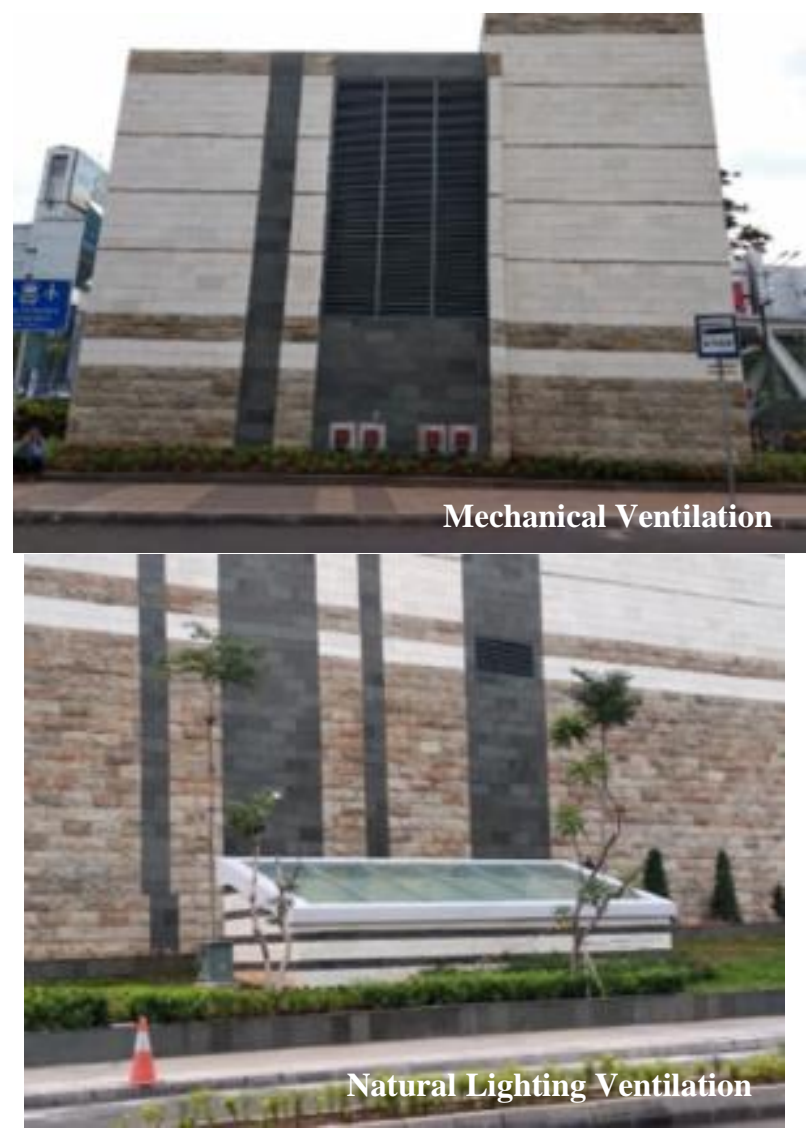

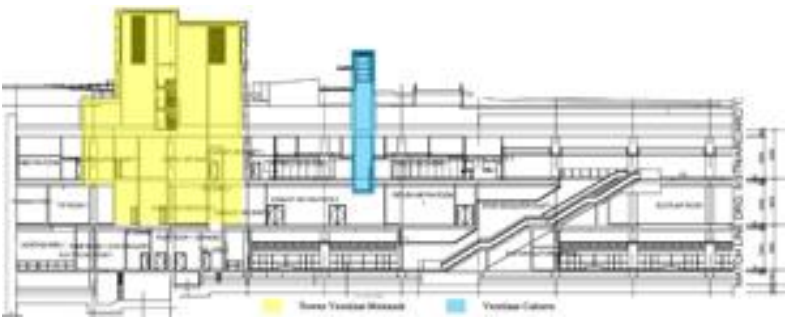

Figure 6. The ventilation on the Station, yellow is Mechanical Ventilation and Blue is Natural Lighting Ventilation.

Source: Authors, 2019

Based on interviews with the Head of the Jakarta MRT Engineering Division, said that at every MRT station, especially the underground, we have been protected by a mechanical ventilation system that is on the north and south sides. The air conditioners that we have conducted not only in the station but also in the MRT of train tunnels, therefore, when there is a fire at the station or tunnel, the suction system and air supply are regulated.

\subsection{Sprinkler}

Based on the survey in the field and interviews with the Head of Technical Division at MRT Jakarta, it can be seen in the evacuation route that there are no sprinklers installed in the corridor of Peron Floor, staircase and the corridor of Concourse Floor is due to prevent slippage when the passengers run away to escape during the evacuation process, while sprinkler installation in the utility and commercial areas because the Concourse needs to be protected from non-fire-resistant materials; thus, we keep trying to be safe, put a sprinkler on the part (Figure 7).

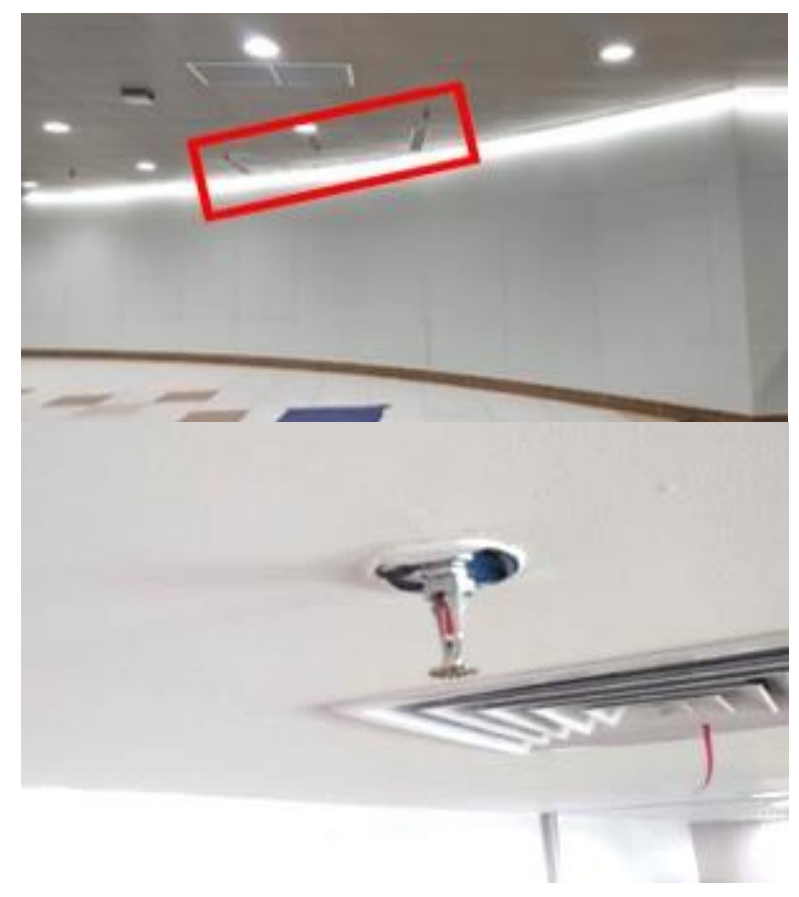




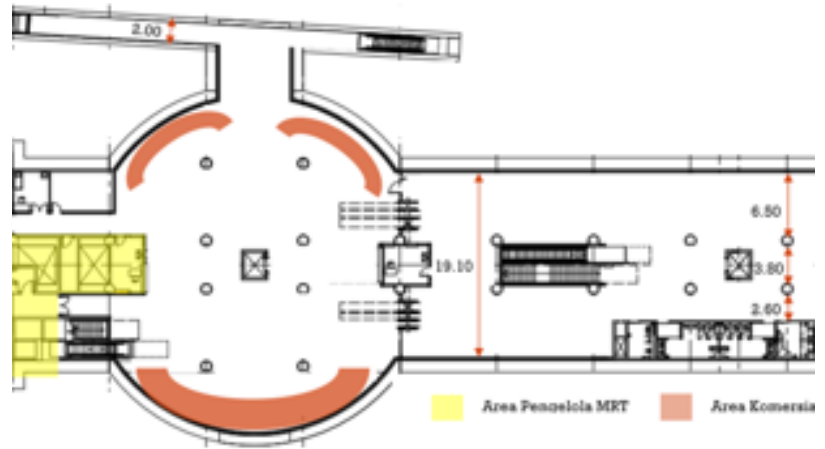

Figure 7. The Commercial area on the Concourse Floor Source: Authors, 2019

\subsection{Assembly Points}

The Station of MRT Dukuh Atas places the assembly point position in front of the entrance/exit door, this is not by the standard, and it will endanger the passengers during the evacuation process (Figure 8).
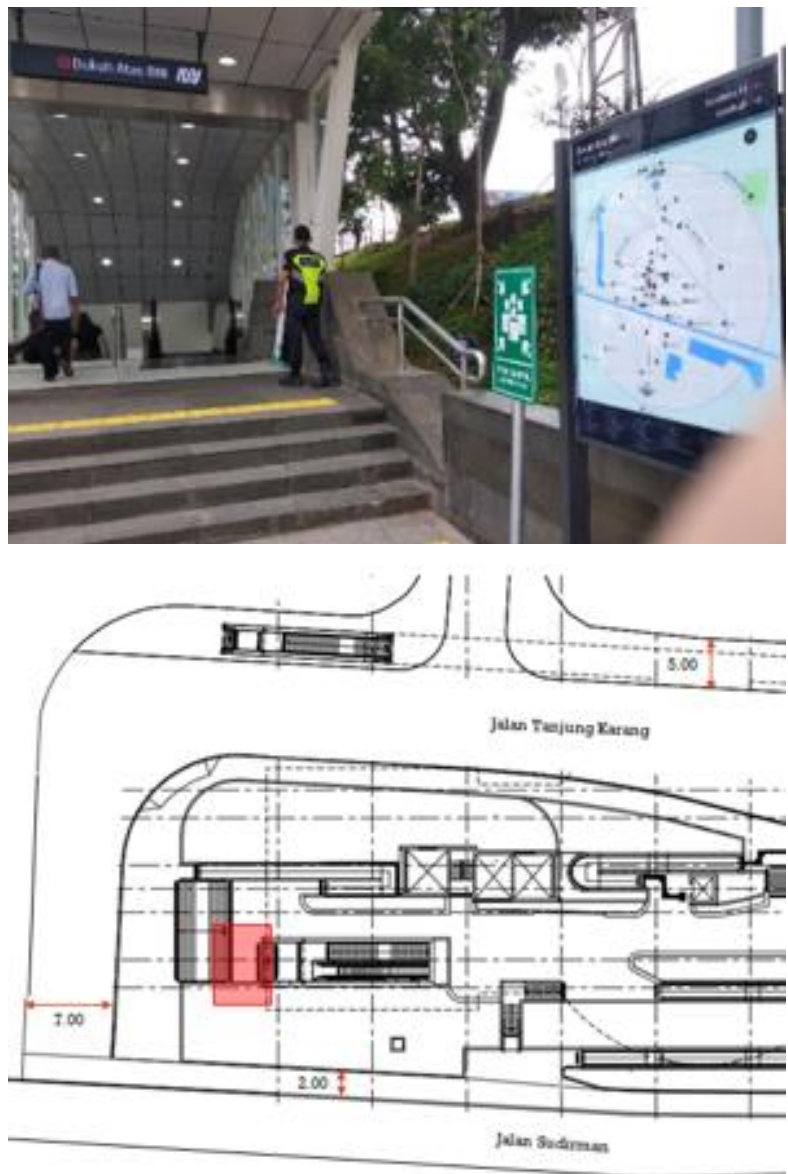

Figure 8. The Commercial area on the Concourse Floor Source: Authors, 2019

\section{CONCLUSIONS}

The results of this research find out that Exit Doors, Staircase, Exit way, Corridors, Ventilation, and Sprinklers can be stated by the regulation of the Nation Fire Protection Association (NFPA) and the Ministry of Land, Infrastructure, Transport, and Tourism (MLIT). However, Escalators, Interior \& Furniture, and the gathering point are stated by the regulations of the Nation Fire Protection Association (NFPA) and Ministry of Land, Infrastructure, Transport, and Tourism (MLIT).

\section{REFERENCES}

[1] Vidal, L. 2013. Urban Rail Transit: Design Manual. Hong Kong: Design Media Publishing.

[2] Barton, H., Marcus G., and Richard G. 2003. Shopping Neighbourhood. London: Spon Press.

[3] Chien, S. W., Chen, W. L., Shen, T. S., Cheng, C. C., Lee, D. C., Hsuse, Y. L., and Chen, T. K. 2004. "A Study on the People Evacuation Safety for the Underground MRT Station." 6th Asia-Oceania Symposium on Fire Science and Technology. Daegu, Korea: International Association for Fire Safety Science. 292-304.

[4] Ching, F. D. K. 2007. Architecture Form, Space, and Order 3rd ed. New Jersey: John Wiley \& Sons, Inc.

[5] Regulation Nation Fire Protection Association (NFPA) 130/2017.

[6] Regulation of the Ministry of Land, Infrastructure, Transport and Tourism (MLIT) 2004. 